\title{
Research on the Development Features and Trends of Characteristic Towns-Based on the Experience of Zhejiang Province
}

\author{
Zihui Pan
}

\author{
School of Civil Engineering and Architecture, Zhejiang Sci-Tech University \\ 928, No.2 Street, Xiasha Higher Education Zone, Hangzhou, 310018 China \\ 906465166@qq.com
}

Keywords: Characteristic Towns; Zhejiang Province; Rural revitalization

\begin{abstract}
The construction of characteristic towns in Zhejiang province has brought new vitality to economic development. This paper summarizes the current research status of characteristic towns, analyzes the successful experience and main features of the development of characteristic towns in Zhejiang province. Propose the prospect of the development of characteristic towns in the background of rural revitalization strategies, look forward to helping the promotion of characteristic towns in various places.
\end{abstract}

\section{Introduction}

In order to adapt to the new normal of economic development, It has implemented the construction of Characteristic town in Zhejiang with developed massive economy but lagging industrial transformation and upgrading, rich traditional elements but insufficient high-end factors, and rapid urbanization but lack of characteristics. By August 2017, the Zhejiang Provincial Government officially announced the establishment of provincial-level characteristic towns. A total of 114 towns were nominated. The provincial government assessed the construction of characteristic towns. The town was either rated as excellent or was warned. Even 6 towns were degraded.

The success of characteristic towns in Zhejiang has been highly recognized and strongly supported by the government. Characteristic towns are rapidly promoted throughout the country. However, there are many problems such as poor infrastructure, lack of public services, serious environmental pollution, uncontrolled construction of agricultural and residential buildings, the disappearance of historical features, and the loss of traditional skills. Land prices have soared, real demand has been seriously inadequate, the ecological environment and traditional culture have been damaged, talents have continued to be lost, and enterprises have been in crisis. [1] Therefore, this paper draws on the experience of the Zhejiang model to explore the development ideas of the future characteristic town.

\section{Overview of Current Research}

Definition of the Concept of a Characteristic Town. The characteristic town of the Zhejiang model is based on a certain characteristic industry, bringing together relevant organizations, institutions and personnel, forming a modern community with characteristics and cultural atmosphere, with four major characteristics of industry, function, form, and mechanism. [2] The National Development and Reform Commission specifically refers to "focusing on characteristic industries and emerging industries, gathering development factors, which is different from the innovative entrepreneurship platform of administrative towns and industrial parks. "

Research on Issues and Norms. In the acceleration of the practice process of characteristic towns, the theoretical circle tries to combine the top-level design to construct a system of evaluation indicators of characteristic towns from multiple dimensions such as industrial dimension, functional dimension, morphological dimension, and institutional dimension [3]. Based on the comparative analysis of the development of characteristic towns abroad, this paper puts forward the suggestion that characteristic towns should use the different industrial characteristics of different regions to 
develop. [2]

Research on the Development Theory and Model of Characteristic Towns. From the perspective of pastoral city theory and precise governance, discuss governance paths such as governance subject, operation mechanism, and innovation system, [4] pointed out that the key to the development of characteristic towns is industrial choice, power mechanism, and policy design. From the perspective of roots, discusses the theoretical basis of the formation of characteristic towns and divides them into three modes: natural endowment, social capital, and market demand according to the differences in the formation of "characteristics". [5] Since 2017, it has been difficult to focus on the financing of specialty towns. Through "government guidance, social investment, and corporate operations," scholars have advocated using the PPP model to solve the problem of capital for the construction of specialty towns. Demonstrate the feasibility of introducing PPP model into the construction of characteristic towns from the aspects of policy orientation, participants 'needs, and operating foundation. [6]

\section{The Main Features of the Characteristic Town in Zhejiang Province}

Relying on a Blocky Economy. In Zhejiang province, almost each county and even small town has its own specialty industries or products. This "massive economy" depends on the accumulation of private economies. There are usually several large companies and hundreds of small companies or even small workshops that provide supporting products or services. Relying on the foundation and experience of "block economy", It promoted the development of characteristic industries. Such as the socks industry in Datang Socks Art Town in Zhuji City is a typical large economic area with socks as a characteristic industry. In this small town with a permanent population of less than 80,000 and an area of only 53.8 square kilometers, there are 5,083 sock-related companies. In 2015, the Datang Socks Industrial Cluster in Zhuji City produced a total of more than 25 billion pairs of socks, accounting for $1 / 3$ of the global market share.

Excavation of Characteristic Industries. The industry such as in Switzerland's Davos town, Greenwich hedge fund town, France's Provence town and other small towns is unique, cultural charm, ecological charm. The small town industrial in Zhejiang province positioning highlights "one town has one industry." First, it will inherit traditional industries. A considerable number of characteristic towns have developed classic industries such as tea, silk, yellow wine, Chinese medicine, celadon, wood carving, root carving and stone carving. Second, it will develop emerging industries. For example, The information economy was developed in Yunqi Town and Dream Town, but in order to highlight the characteristics, they are different: Yunqi Town's features is the development of large data and cloud computing; The Dream Town focuses on "Internet entrepreneurship + venture capital."

Highlight The High-end Leadership. The first is to gather the high-end elements of the industry, including talents, technology, equipment, etc., build an industrial Highland, and become a regional or national or even global leader of the industry. Each town is an innovation platform, with a combination of innovation factors, collaborative innovation, science, technology and finance, and vigorous development of innovation and entrepreneurship. It will emphasize the application of new technologies, promote the integration of "Internet + " and other new technologies with traditional industries, actively cultivate new forms of business, upgrade the value chain, and become a new carrier for industrial transformation and upgrading. It has inherited history, such as tea, silk, and yellow wine, not only inherit the essence of craft culture, but also lead the industry to innovate and develop, and inject new vitality into traditional industries.

Focus on Land Conservation. The planned area of characteristic towns in Zhejiang province is generally controlled at about $3 \mathrm{~km}^{2}$ and the construction area is generally controlled at about $1 \mathrm{~km}^{2}$. This is to save land for construction and to use it intensively. At the same time, the government does not set up a special Management Agency to reduce administrative costs. For example, in Yunqi Town, the total planned land area is $3.5 \mathrm{~km}^{2}$, It has a planned area of $3 \mathrm{~km}^{2}$ in Longwu Tea Town, and the total planned investment is 5 billion yuan. The planned land for Tonglu Health Town is only $2.6 \mathrm{~km}^{2}$, and the total planned area of the Cross-Trade Town is approximately $2.9 \mathrm{~km}^{2}$. 
A Huge Investment. Small towns require capital investment in infrastructure construction, talent introduction, industrial development, and project promotion. The Zhejiang Provincial Government stipulates that the characteristic towns in the four major industries of environmental protection, health, fashion, and high-end equipment manufacturing must complete an effective investment of 5 billion yuan within three years; The characteristic towns of the three major industries of the information economy, tourism, finance, and historical classic industries must complete an effective investment of 3 billion yuan within three years. For example, the first batch of 37 specialty towns in Zhejiang attracted more than 3,300 companies, completed an investment of 48 billion, and 5 towns have invested more than 2 billion.

Innovative Operating Mechanisms. How to meet the financing needs of characteristic towns has become one of the difficult problems that need to be solved in developing characteristic towns all over the country. The positioning of Zhejiang characteristic towns is "government guidance, corporate main body, and market operation", highlighting the main position of enterprises, making private enterprises, central enterprises, and provincial state-owned enterprises actively participate in the construction of characteristic towns. The government mainly does: planning, supporting infrastructure, factor protection, ecological and environmental protection, creating a good policy environment, and attracting all parties to build characteristic towns. Enterprises are mainly engaged in industrial development, talent introduction, marketing, project promotion, and benefit pursuit.

\section{The Role of Characteristic Towns in the Rural Revitalization Strategy}

The Characteristic Town is the Bridge Link of the Rural Revitalization. Through the construction of characteristic towns, urban residents and capital can go to the countryside, rural residents and land to enter the city, and promote the overall development of urban and rural areas in two-way interaction. From the point of view of population flow and spatial agglomeration, the process of rural revitalization is the process of optimal allocation of population and industry between urban and rural areas, urban-rural interaction and integrated development. Urbanization can't be separated from the integration of rural population and factors, and the revitalization and modernization of the countryside can't be separated from the drive of the city to the countryside and the longing of the urban population for the countryside.

Characteristic Towns are the Engine of the Rural Revitalization. Through the construction of characteristic towns, it can drive rural characteristic industries and play a leading role in rural revitalization. In contrast to the process of industrialization and urbanization in Europe, a number of characteristic towns have been formed. For example, around the southern French tourist city of Nice, the movie Holy Land of Cannes, the entertainment paradise Monaco are all distributed within half an hour. Similarly, the division of labor and coordination between German towns and cities is high, the degree of specialization is high, the economic efficiency, the level of service, and the per capita income are relatively close, and the States, counties, and townships are independent autonomous entities, and there is no subordinate.

The Characteristic Town is an Important Platform of the Rural Revitalization. The characteristic town is the key to the integrated development of urban and rural areas. With the characteristic town as the carrier, the process of rural revitalization can be accelerated. Rural revitalization requires a strong leader and carrier to concentrate and gather the beautiful environment, cultural customs, historical culture, and special resources of the countryside in space, promote the development of characteristic industries, and create a characteristic town to carry the industry and population. Attracting the inflow of urban resource factors and accepting the spill-over of urban consumption. The integration of small towns into the countryside is in line with the current central concept of the development of special towns, and it has also fundamentally enhanced the endogenous development capacity of the countryside. 


\section{Development Trends of Characteristic Towns under Rural Revitalization Strategy}

Request for Integrated Planning from the Spatial Dimension. Planning is an important means of leading orderly development. The characteristic town is a systematic project covering industries, ecology, space, and culture. Most of the features of the town are located at the junction of urban and rural areas and are relatively independent of the city. Both have the service function of the city, which is a new space for the proliferation and reorganization of high-end elements of the city. It is part of the urban system. Different from the traditional planning ideas, the content of the special town planning shows a diversified, multidisciplinary and multi-perspective. It must have both conceptual planning, industrial planning and tourism planning, at the same time it must have micro-urban design. Therefore, it is a kind of plan that is both pragmatic and pragmatic. [7] It is necessary to combine local factors such as geography, history, humanities and other factors. The planning should be a kind of "creating conceptual planning".

It should not only be a strategic study of top-level design, but also have a conceptual space design and construction project implementation plan. The first is to determine the characteristics of the theme. From the perspective of the location of the town and the larger scale of the region, based on the three elements of "characteristic industries, resource endowments, and cultural heritage", the characteristics of the town can be combed, refined, and summed up. Next is the location of the town. The main consideration is that the development and construction of the town may have a positive effect, that is, the extent to which the site has played a unique advantage in the region, and the negative effect of the town construction on the overall development of the surrounding area, that is, the potential development of the site. The degree of negative impact on the development of the surrounding area.

Request the Whole Process Management from the Time Dimension. The characteristic town is not a project, but includes the whole process of planning, development, construction, and operation management. Therefore, to establish the idea of full management, it is not only important to attach importance to the declaration and creation of the previous period, and the subsequent operation and management are more important.

In the project planning stage, it is necessary to base on the functional orientation and orientation of the plan and combine the space layout requirements to determine the content, scale, location and construction intention of each specific project during the creation period. In the phase of investment promotion, the government and the market investors should be distinguished according to the actual situation. In the construction stage, it should take into account factors such as the willingness of the construction body to invest and the possibility of land supply, arrange annual investment and land supply plans. In the operation stage, according to the development model, fund balance, benefit analysis, etc., according to the actual situation of each town, proposed a targeted operation plan.

Request Accurate Location from the Industrial Dimension. Due to the difference in the level of industrial development, the industrial development of the characteristic towns must be precisely positioned, could not blindly chase the trend. The government should guide and support the industry and promote a certain industry to become a champion. For example, the industries of the first batch of characteristic towns in Zhejiang Province are: 5 in the information economy industry, 2 in the health industry, 5 in the fashion industry, 8 in the tourism industry, 4 in the financial industry, 6 in high-end equipment manufacturing, and 7 historical classic industries. It need to be explored to the core industrial elements of the characteristic town. Therefore, in the construction, we should focus on the integration of "productive cities" and the construction of ecological bases, so as to achieve a win-win situation between industrial development and urban construction. Based on the characteristics of resource endowment, location environment, history and culture, and industrial agglomeration, we will construct dominant industries with distinctive advantages, and construct a pattern of large industries in small towns in the orientation of differences and division of fields.

Require Integration from Functional Dimensions. Cultivate emerging industries, especially those in the information economy category; Construct high efficient innovation incubator; Promote the upgrading of traditional manufacturing industries; Expand the development space of classical 
culture industry; The integration of knowledge service industry and characteristic industry; Promote the serviceability of characteristic industries. That is, in the limited space to achieve the full integration of industrial functions, tourism functions, cultural functions, community functions.

\section{Summary}

As an attempt at a new type of urbanization, a characteristic town can not only produce new economy and new energy, but also create new development space for livable and suitable industries. However, if development is not done properly, it will cause problems of waste of resources and environmental damage. Therefore, according to the specific situation, each region should choose a development model that is suitable for the local area.

\section{References}

[1]W. Wu, X.X. Tang, C. Liu: The Development History and Prospects of Characteristic Towns, Chinese Landscape Architecture, vol.33 (2017) No.9, p.52-54.

[2]L.B. Wei, X.J Shi: Reflections and Suggestions on the Construction of Zhejiang Characteristic Town. Zhejiang Social Science, (2016) No.3, p.28-32

[3] Y. Z. Wu, Q. H. Chen, X.H. Zheng: Indices System and Evaluation Method of Characteristic Town Development, Planners, vol.32(2016) p. 123-127.

[4]X.Q. Min: Characteristic Towns and Their Building Path From the Perspective of Accurate Governance, Tongji University Journal Social Science Section, vol.27(2017) No.5, p.55-60.

[5] X.D. Fu, Y.W. Jiang: Discussion on the Development Model of Characteristic Towns in China from the Perspective of Embeddedness, China Soft Science, (2017) No.8, p.105-111.

[6] G. D. Ma, T.H. Wang, S. Q. Zheng: Research on the Application of PPP Model in Characteristic Town Projects, Construction Economy, vol.38(2017) No.8, p.55-58.

[7]F. Hua, J.B. Lu: A Research on Towns in Features of Characteristic-Hangzhou, Journal of Urban Planning, Vol.235(2017) No.3, p.78-84. 